\title{
ESTADO CONSTITUCIONAL BRASILEIRO NA SOCIEDADE COMPLEXA: A IMPORTÂNCIA DAS POLÍTICAS PÚBLICAS
}

\author{
Brazilian constitutional state in complex society: the importance \\ of public policies
}

\section{Kátia Silene Sarturi}

Procuradora Municipal em Campo Grande (MS, Brasil). Mestre em Direito e Doutora em Direito. ${ }^{1}$

\section{Resumo}

O ensaio propõe uma reflexão sobre a importância das políticas públicas na sociedade complexa, tendo por parâmetro - Estado constitucional brasileiro. Para tanto foram apresentados conceitos de sociedade complexa e políticas públicas, contextualizando com o constitucionalismo brasileiro, enfrentando a relação do direito com a política.

Palavras-chave: Estado constitucional de direito. Sociedade complexa. Políticas públicas.

\section{Abstract}

The essay proposes a reflection on the importance of public policies in the complex society, having as parameter the Brazilian Constitutional State. For that, concepts of complex society and public policies were presented, contextualizing with Brazilian constitutionalism, facing the relationship of law and politics.

Keywords: Constitutional state of law. Complex society. Public policy.

\section{Sumário}

1. Considerações iniciais; 2 . Notas a diferenciar (não separar) direito e política; 3. Sociedade complexa; 4. Constitucionalismo a partir da $2^{\mathrm{a}}$ Guerra Mundial na Europa e após a ditatura no Brasil; 5 . Conceituação e definição de parâmetros de escolha; 6. Conclusões a evidenciar a importância das políticas púbicas; 7. Notas; Referências 


\section{CONSIDERAÇÕES INICIAIS}

No Brasil e em diversos países do mundo percebe-se uma maior proeminência do Poder Judiciário na condução dos ditames relativos a políticas públicas. ${ }^{2}$ Essa nova atuação está a refletir uma mudança paradigmática na teoria tripartite dos poderes, ao menos se pensada na sua concepção clássica, que mesmo naquele pensamento já não admitia separação radical entre os Poderes, mas, ainda assim, considerada como fundamento para a intocabilidade de temas como políticas públicas pelo Judiciário.

Tem-se por ativista a tendência do Poder Judiciário em substituir os demais poderes nas atribuições a estes inerentes, principalmente em face de condutas omissivas destes Poderes $^{3}$ ou como uma singular atuação para materializar direitos fundamentais. É fato que todo o Poder Judiciário, movimento que é capitaneado pelo Supremo Tribunal Federal, tem ganhado destaque em temas que antes da Constituição Federal de 1988 somente seriam tratados pelos demais Poderes.

Em matéria de política pública, questiona-se: em meio às crises institucionais enfrentadas pelos Poderes Executivo e Legislativo deste país, considerando que a sociedade não se sente tutelada e/ou representada por esses Poderes em sua totalidade, somadas às omissões legislativas e falta de instituição de políticas públicas que atendam a todos da sociedade (incluindo as classes minoritárias), bem como a existência da rigidez de normas Constitucionais analíticas, que trazem uma gama de direitos fundamentais do ser humano, poderia o Judiciário permanecer inerte (ou decidir nos estritos limites da interpretação clássica das normas) perante demandas acionadas pelo descumprimento de direitos fundamentais? Na sociedade complexa, o enfrentamento de temas envolvendo políticas públicas também é tema de complexa interpretação constitucional (trocadilho).

A compreensão do Estado no século XXI, em especial no Brasil, é substancial para a compreensão da sociedade complexa, pois os desafios ditos da atualidade, como fenômenos ligados à globalização, a crise da democracia representativa, crises econômicas, questões migratórias, pandemias, problemas ambientais, terrorismo, ${ }^{4}$ desafiam a formação de um novo Estado, com perfil reorientado pela formação de blocos políticos e econômicos, com novo olhar acerca da soberania, ${ }^{5}$ a exigir uma nova postura do Direito, posto que o Estado é responsável pela produção de normas e instituições que precisam "dar conta" das expressivas mudanças sociais e jurídicas, que exigem políticas públicas capazes de encadear as ações do governo que realizem efetivamente as promessas constitucionais. ${ }^{6}$

\section{NOTAS A DIFERENCIAR (NÃO SEPARAR) DIREITO E POLÍTICA}

As nítidas e essenciais relações entre o direito e a política não os transformam na mesma substância, mas com certeza são partes do mesmo alforje ${ }^{7}$ chamado Poder.

Conceitualmente, o direito busca criar padrões de comportamentos e sanções pelo descumprimento do comportamento desejado, tendo assim uma função estabilizadora. Já à política cabe determinar e realizar os fins coletivos.

O direito traz as formas de se organizar e trazer contornos bem definidos para uma atuação política e esta tem como produto e instrumento o próprio direito. A distinção entre 
política é direito é fugaz principalmente em face da Constituição Federal de 1988 que constitucionalizando direitos, não é apenas um instrumento de proteção e limitação de poder, mas sim um guia de orientação para o exercício do poder que nunca pode destoar da busca da implementação dos direitos constitucionais.

Desta forma, em uma sociedade complexa, não há rigidez em qualquer separação. As vontades decorrentes do processo político motivado por tensões culturais e sociais, devem subsidiar o arcabouço jurídico a permitir se alcancem os objetivos almejados por uma determinada sociedade. Por isso, o direito é dinâmico e, por ser produto da política, está sujeito a avanços e também a regressões. ${ }^{8}$

Não se descuida, entretanto que, no Brasil, por ser nossa Constituição analítica e programática, não se abrem muitos espaços ao legislador. Com esse panorama o direito tem por principal função permitir o questionamento da validade e legitimidade das próprias normas produzidas no processo legislativo político. Temos uma vinculação constitucional da legislação. A política molda o direito por meio de normas gerais, mas a interpretação e aplicação aos casos concretos se desapega do conteúdo político. ${ }^{9}$

Percebe-se dessa forma a nitidez da separação entre o juiz e político, separação esta inclusive determinada pela Constituição, havendo uma separação institucional. A regra é que as condutas dos cidadãos sejam pautadas pelas diretrizes dos comandos legais decorrentes do processo político. Apenas quando há conflitos, é que a tutela do poder judiciário entra em cena por meio da jurisdição, explicitando o conteúdo da norma e a aplicando ao caso concreto. ${ }^{10}$

E há um sistema constitucional de proteção entre a política e a aplicação do direito. Os órgãos da jurisdição estão protegidos das interferências políticas dos órgãos públicos que possuem poder de decisão, bem como dos partidos políticos. Mas o processo político também é protegido pela existência de regras e limites que os tribunais devem obediência quando da aplicação da lei ao caso concreto. Quando se afirma que a Constituição limita a política não se está a afirmar que há total juridicização da política, sob pena de se converter o político em um mero administrador, o que não se coaduna com a própria política que produz e transcende o próprio direito. ${ }^{11}$

Quando surge o Estado Democrático e Social de Direito, abandonou-se a discricionariedade absoluta dos Estados liberais, estando os governantes limitados em seu agir às determinações de cunho social determinadas pela Constituição. Daí se permite um controle político exercido pelo poder judiciário. A Constituição em si, documento político máximo da nossa nação, que refletiu, quando de sua edição, os aspectos sociais de conflito, com teor revolucionário, principalmente no que se refere à determinação de direitos, faz com esses direitos sejam bastante próximos da Política. ${ }^{12}$

$E$ as escolhas feitas pelo Poder Constituinte, originário e ilimitado, não podem ser comprometidas pela inércia do Poder Constituído, seja em decorrências das ações dos poderes Legislativo ou Executivo. Há na Carta Magna um nítido viés de preocupação social, sendo que a já definição constitucional de direitos sociais configuram direitos públicos subjetivos passíveis de serem exigidos em face do Estado. ${ }^{13}$ Assim, o Poder Judiciário pode 
analisar questões políticas, mas estando limitado onde há discricionariedade deixada pela Constituição ao administrador e legislador, que permitem a estes a escolha das políticas adequadas, desde que qualquer das escolhas respeitem as disposições da Constituição.

Desta forma, não se pode negar a existência da jurisdição política, para fins de verificação da legitimidade da política adotada. Esta atividade judicial, embora excepcional, eis que não cabe ao Poder Judiciário a formulação de políticas públicas, quando o administrador ou legislador descumprirem mandamentos constitucionais, comprometendo a integridade dos direitos garantidos pela Constituição, é totalmente legítima e necessária em um Estado Democrático e Social de Direito, sendo o Poder Judiciário um papel de controlador de última instância das decisões políticas dos demais poderes, quando o paradigma é a Constituição.

Por conseguinte, a função política pode ser verificada nas funções decorrentes do próprio poder político, quais seja, as funções legislativa, executiva e a judicial. ${ }^{14} \mathrm{~A}$ constituição, de forma política, delimitou, em muito as políticas públicas a serem seguidas, e, como cabe ao Poder Judiciário a verificação de conformidade com a Constituição, se impõe na prática perfil político desse poder.

\section{SOCIEDADE COMPLEXA}

A característica principal de uma sociedade complexa é a existência de riscos e incertezas, além da constatação de que as promessas feitas pela modernidade nunca se concretizarão, sendo certo, ainda, que as sociedades não necessariamente devem caminhar para uma mesma finalidade, que é o desenvolvimento econômico.

Quanto ao tema, devem ser destacadas as características de uma "sociedade de riscos", conceito trazido em 1980 pelo sociólogo alemão Ulrich Bech. A análise de tais traços é importante, na medida em que o pânico gerado na sociedade possui reflexos no Estado, que se vê responsável na solução dos problemas, obrigando a estender seus braços a amparar a complexa sociedade.

Em sua obra "La sociedad del riesgo", Ulrich Bech, diferencia escalona as modernidades. A primeira (simples ou industrial) formara-se a partir do século XVIII, caracterizando-se por ser uma sociedade baseada no Estado territorial, nacional e fortemente industrializado. Destaca o autor que a segunda modernidade, na qual vivemos, ("modernização da modernização", "segunda modernidade" ou "modernidade reflexiva"), escancara as insuficiências e as antinomias pregadas pela primeira modernidade, tentando superar os desafios da globalização, da individualização excessiva, do desemprego, do subemprego, da revolução dos gêneros e dos riscos globais da crise ecológica e da voracidade e volatilidade dos mercados financeiros. ${ }^{15}$

É certo que o homem sempre tenha estado envolto a riscos, ${ }^{16}$ mais previsíveis, pois ligados às guerras, fome e doenças, a sociedade moderna, por meio da tecnologia e da técnica, embora embasada na busca do controle total sobre as situações de ameaça, desenvolveu riscos que fogem a qualquer possibilidade de controle. ${ }^{17}$

As duas grandes guerras mundiais do século XX que deixaram mais de 100 milhões de mortos mostrou a total impotência humana em viver em um mundo repleto de incertezas, 
cujo resultado fora o Holocausto, o fascismo, os desastres ambientais e nucleares e os imperialismos ideológicos comunista e americano.

A certeza que a ciência pregava não tem mais lugar. As religiões, aptas a fazer as sociedades agirem em cooperação já estão sendo desbancadas pelo Homo Deus. ${ }^{18}$

Conforme destaca Harari, a modernidade é um contrato, sendo que "todos nós aderimos a ele no dia em que nascemos, e ele regula nossa vida até o dia em que morremos". ${ }^{19}$ Ocorre que nesse contrato, a incerteza se mostra presente em todos os lugares, ${ }^{20}$ inclusive nas ciências e religiões.

Por outro lado, a constatação de que a natureza em si mesma teria como único objetivo servir ao indivíduo não mais subsiste, pelo esgotamento ocasionado pelo desenfreado consumo mundial. O ciclo vicioso de busca de desenvolvimento econômico para se solucionar problemas sempre traz mais problemas a serem resolvidos com mais desenvolvimento econômico.

Maffesoli, analisando as características da modernidade, ressalta que "a projeção no futuro não possui grande sentido; o trabalho é relativizado por muitos centros de interesse; o quantitativo cede lugar ao qualitativo e ao desejo de fazer da vida uma obra de arte". ${ }^{21}$

Já se percebeu que a ciência humana, bem como toda a sua tecnologia, não resolveram os problemas causados pela natureza ao homem causados por este àquela.

E nesse panorama surge o direito, como aquele que resolveria todas as diferenças. Os bens naturais, por serem naturalmente limitados e os interesses do homem ilimitados, fazem surgir os conflitos de interesses, eis que para se garantir todos os direitos, o interesse de um indivíduo deve prevalecer sobre o do outro, necessariamente. Surgem assim as pretensões resistidas. As denominadas lides. E essas são resolvidas pelo Poder Judiciário.

As multinacionais e também os problemas ambientais não respeitam, entretanto, as fronteiras da Justiça. A dicotomia entre a necessidade do progresso econômico e a consequente produção de riscos afetam o mundo global. ${ }^{22}$

É certo que, embora o potencial destrutivo da tecnologia alcançado pelas sucessivas guerras tenha evidenciado a capacidade de destruição em massa, constatando-que na verdade o ser humano age como um vírus, também proporcionou o surgimento de diversas novas tecnologias presentes em nosso cotidiano, a exemplos os smartphones, aplicativos de comunicação, diversos remédios, veículos e diversos equipamentos eletrônicos, todos a tornarem a nossa vida mais fácil e significante.

Entretanto, a esperada sensação de segurança e prazer que tais novidades poderiam nos trazer sucumbem vez ou outra à intranquilidade dos desastres ambientais, dos extremismos, da ausência de valores, o que faz a sensação de insegurança ser sentida em todos os lugares, mesmo no interior de nossas protegidas residências.

Além de ter que saber repartir de forma justa a riqueza e assegurar a igualdade, também é necessário repartir e distribuir a destruição e os riscos a todos como a extinção de espécies animais e até mesmo de grupos étnicos, os desastres ambientais, as contaminações 
químicas, o esgotamento hidráulico, entre vários outros problemas. Os avanços médicos, morais e sociais que trazem consigo uma maior obrigatoriedade do Estado em relação ao cidadão, trazem consigo algo muitas vezes não quisto, mas que veio junto em um pacote único proveniente da venda casada que a geração de riquezas proporciona. ${ }^{23}$

Os riscos não respeitam as divisões sociais, embora os menos abastados sempre se submetam a eles de forma mais exposta. Mesmo na segurança de seu lar, com segurança monitorada, bem alimentado muitas vezes com transgênicos e com recursos mais que suficientes para o gozo da vida com as facilidades proporcionadas pela modernidade, o indivíduo de uma classe social abastada fica totalmente impotente frente à poluição do ar, frente às notícias que chegam pelas redes sociais, bem como à subversão e inversão de valores que chegam por meio de programas televisivos que muitas vezes tornam o indivíduo em um mero e insignificante telespectador que espera que algo ou alguém irá sempre resolver os seus problemas. ${ }^{24}$

É certo que compartilhamos uma era plural em que a aceleração das informações e facilidades do dia a dia fez o homem abandonar as suas certezas ${ }^{25}$ como a religião, a própria ciência, ${ }^{26}$ as forças do meio ambiente que aos poucos vai constantemente se exaurindo e até a moral, estando saboreando o ser humano as vantagens e responsabilidades de se sentir como o Deus responsável pela própria existência.

A globalização que pode ser conceituada como a "intensificação das relações sociais em escala mundial, que ligam localidades distantes de tal maneira que acontecimentos locais são modelados por eventos ocorrendo a muitas milhas de distância e vice-versa", ${ }^{27}$ a mundialização do direito e o mercado globalizado e sem fronteiras reduz a maioria dos indivíduos, ora a meros produtores ora a meros consumidores.

As sociedades e os indivíduos, sejam eles ricos ou pobres, desenvolvidos ou não, não mais enfrentam a localidade de nações ou pessoas inimigas, mas riscos e perigos onipresentes, seja ele um ataque terrorista, um assassinato em massa em escolas ou igrejas, acidentes ambientais com potencial lesivo ainda que tenha ocorrido do outro lado do mundo, um vírus de computador, ou imagens e personagens que levam crianças e adolescentes a se suicidarem.

A Pós-Modernidade se encontra desestruturada. Com tal percepção, Franklin Baumer destaca:

o homem do século XX perderá seu ponto de referência dentro do universo, perdendo 'segurança sociológica'. Ressalte-se que as duas guerras mundiais deixaram à mostra as angústias do homem que não consegue resolver seus problemas sociais. Existe um grande poder através da tecnologia versus impotência e destruição na busca da resolução a problemas políticos. Assim, nunca o homem em toda a idade moderna havia se olhado de maneira tão baixa, uma vez que esta visão substituía a idéia de homem dotado de razão e senhor de si (enfraquecida desde Darwin). Copérnico destruiu a ilusão cósmica de que o homem era o centro do universo; Darwin destruiu a do homem de ser um ser superior e diferente dos animais e Freud, com a psicanálise, dá o maior golpe: o homem nem sequer era dono de sua casa, o ego não dirigia toda a vontadee trabalho do espírito. ${ }^{28}$

Ainda, nas palavras de Arenhart: 
o mito da Modernidade, propriamente, consiste em fazer o Outro crer que sua submissão ao superior é feita para o bem de todos, de modo a civilizá-lo, modernizá-lo, ou seja, a dominação adquire um caráter de 'emancipação', 'útilidade', 'bem' do 'bárbaro'. Consiste em vitimar o dominado considerando-o causa culpável de sua própria vitimação e atribuindo-se ao sujeito moderno plena inocência com respeito ao ato sacrificial; o sofrimento do conquistado seria o sacrifício ou o custo necessário da modernização. ${ }^{29}$

O homem pós-moderno, destituído de fé e de razão, de território, de projeto e de crença em uma certeza de um futuro previsível, vê a solução no presenteísmo e no consumismo, capazes de minimizar sua depressão. Por não ter conseguido responder todas as dúvidas do ser humano, mas, ao contrário, por demonstrar a incerteza dos próprios fenômenos, as ciências, sejam humanas ou exatas, são sempre cobradas e muitas vezes questionadas por suas conclusões.

\section{CONSTITUCIONALISMO A PARTIR DA $2^{\mathrm{a}}$ GUERRA MUNDIAL NA EUROPA E APÓS A DITATURA NO BRASIL}

O constitucionalismo contemporâneo (para parte da doutrina, o neoconstitucionalismo) apresenta características específicas decorrentes do pós segunda-guerra, como reações ao nazismo e fascismo. Ter-se-iam novidades, o que o diferenciaria do constitucionalismo anterior, por meio de particularidades que se apresentam, notadamente em relação à dignidade da pessoa humana, redução das desigualdades, valorização de serviços como educação e assistência social. A Constituição teria passado de um documento essencialmente político para uma norma jurídica suprema, com normatividade e imperatividade extremas, com superioridade sobre quaisquer outras normas jurídicas de um Estado, que inclusive devem sempre partir dos ditames da própria Constituição. ${ }^{30}$

Enquanto no Brasil o marco do fenômeno do direito Constitucional contemporâneo se dera com a Constituição de 1988 no período de redemocratização, na Europa o fenômeno é mais antigo datando do pós-guerra, notadamente na Alemanha e na Itália.

Antes da segunda guerra mundial, no velho continente a cultura jurídica privilegiava totalmente a lei em sentido formal, sendo esta editada pelo Poder Legislativo fonte quase exclusiva do Direito. Não se atribuía muita força normativa às Constituições geralmente encaradas como documentos políticos a inspirarem o legislador, não podendo suas disposições serem invocadas perante o Poder Judiciário para a defesa de direitos. ${ }^{31}$ Se algum direito fundamental previsto em alguma constituição não tivesse sido previsto por lei, não era dotado de força vinculante.

Na Europa, o cientificismo do Direito Constitucional fora impulsionado aos países de tradição romano-germânica pela Constituição Alemã (Lei Fundamental de Bonn - 1949). Também houve impulsionamento pela Constituição da Itália de 1947.32 Mais tarde, com a redemocratização e reconstitucionalização da Espanha (1978) e de Portugal (1976) houve destaque no debate sobre o direito constitucional, notadamente pelo reconhecimento de a Constituição ser um instrumento jurídico e político. ${ }^{33}$

Nesses países percebeu-se que também as maiorias, ainda que políticas, podem se 
aproximar da barbárie, como o fizera o Nazismo em relação à minoria judia na Alemanha. Essa percepção permitiu se alçar à Constituição os direitos fundamentais, mas agora dotados de força normativa.

Em similitude ao ocorrido na Europa, no Brasil também após um período de ditadura com autoritarismo, foi com o processo de redemocratização no Brasil que se atribuiu maior força normativa ao Direito Constitucional. A Carta de 1988 fez do Direito Constitucional o centro real de poder, diversamente do que sempre ocorrera no país anteriormente. ${ }^{34} \mathrm{~A}$ Carta Magna tem o mérito de ter feito sem naufrágios a travessia no rio revolto a separar o leito de um regime autoritário e o de um Estado Democrático de Direito. Passou a ser símbolo de conquistas e uma superação da histórica indiferença que se tinha em relação às Constituições. ${ }^{35}$

O neoconstitucionalismo, seja na Europa seja no Brasil, surgiu do reencontro da ciência jurídica e da filosofia do direito, o que se dera por meio do recurso aos princípios abrigados de forma explícita ou implícita pela Constituição, que passa a figurar em uma ordem superior. ${ }^{36} \mathrm{O}$ reconhecimento de força normativa aos princípios jurídicos, que passaram a moldar a própria aplicação do direito em qualquer das áreas, o abandono do mero formalismo em si pelo recurso a técnicas de raciocínios jurídicos mais abertos e a reaproximação do direito e da moral com a consequente judicialização da política e da própria relação social com as luzes pairando mais no Judiciário do que no próprio Legislativo e Executivo, são a tônica principal desse novo fenômeno. ${ }^{37}$

As constituições passaram assim a trazer regras e princípios com forte valor axiológico, com abertura e indeterminação semânticas, frutos de decisões substantivas sobre temas que antes não eram abordados nas Constituições, como economia, temas afetos à família, ao trabalho, educação, saúde, dentre diversos outros temas. É como se tivesse se materializado a constitucionalização da ordem jurídica, o que tinha reflexos nos mais diversos ramos do direito. Na interpretação de tais regras e princípios constitucionais, a mera subsunção já não se mostrava suficiente, demandando novas técnicas e estilos hermenêuticos.

Muitos dos princípios constitucionais podiam até mesmo conflitar entre si, o que fez se aplicar pelo Poder Judiciário de novas técnicas de argumentação jurídica, como a da ponderação e da proporcionalidade, com constantes imersões em campos afetos à moral disciplinada na ética. ${ }^{38}$

No modelo legalista ou democrático, a Constituição fixa as regras do jogo político, mas sem dele participar. Determina ela quem manda, mas não o que se manda. Não seria a Constituição o oráculo a resolver todos os problemas, mas traria os caminhos a serem seguidos mediante escolha do legislador. ${ }^{39}$

\section{CONCEITUAÇÃO E DEFINIÇÃO DE PARÂMETROS DE ESCOLHA}

Políticas públicas seriam os programas, o conjunto de ações, os arranjos institucionais das estruturas sociais de fodo (modo) a refletir as relações entre sociedade civil, mercado e governo, e a definir os padrões para se buscar a consecução de objetivos previamente estabelecidos. Política pública pode ser vista como o caminho para se checar um objetivo, 
muitas vezes já predeterminado. Nessas relações institucionais, percebe-se que as instituições são mais importantes que os indivíduos. ${ }^{40}$

O adjetivo "público" evidencia que se está a falar dos caminhos trilhados pelo poder público, em regra o Poder Executivo, por meio de seus governos eleitos em esfera federal, estadual, distrital ou municipal, para mandato determinado. Isto porque a política, ainda que vise atingir objetivos públicos, podem ser desenvolvidas por sujeitos não integrantes do poder público. Logo, o tema que por hora nos interessa é a política pública desenvolvida por órgãos estatais.

A política pública, desta forma, envolve decisão, escolha, opção da forma de se meIhor alocar os recursos. É a livre escolha de meios para se atingir objetivos. Os objetivos, por sua vez, no caso brasileiro, na maioria das vezes não são de livre escolha pelo Administrador, por já estarem previstos na Constituição Federal. Desta forma, ao administrador cabe decidir o melhor caminho a ser seguido para se atingir os objetivos pré-determinados.

O deixar de fazer algo também decorre de um processo decisório e pode demonstrar que a omissão pode ser fruto de uma determinada política pública. Ou seja, a ausência decisória pode também ser vista como uma política pública. ${ }^{41}$

Falar desta forma em política pública envolve abordar as instituições públicas, suas regras, procedimentos e esquemas de cognição que fornecem o significado de suas ações e relações com os indivíduos. Essas relações entre as instituições e os indivíduos, de modo a se ter a legitimidade nas escolhas, ao longo da história pátria, mostrou-se ora patrimonialista, ora clientelista, ora corporativista, gerencialista e ora baseada no mérito. ${ }^{42}$

Com a Constituição Federal de 1988 e seu sopro de redemocratização, foram criadas várias formas de participação direta da sociedade na escolha das políticas. Isto se deu por meio da criação de conselhos, da definição das atribuições constitucionais dos Municípios, com ênfase para a descentralização, surgindo a accountability.

$\mathrm{Na}$ outra ponta, a Constituição Federal também trouxe normas que afetam a estrutura para a tomada de decisões e para a execução das políticas públicas. As rígidas e burocráticas regras seguidas pela administração direta muitas vezes são estendidas para a administração indireta. Criou-se regime jurídico único para o serviço público federal, o que fora reproduzido em muitos casos pelas esferas municipais e estaduais, o que limita a inovação e a flexibilização na atuação e também nas formas de contratação. ${ }^{43}$

A Constituição também tem um papel muito importante na política, eis que, por ser extremamente analítica, já define os vários objetivos a serem conseguidos pelo administrador. Possui a Carta Magna viés social, sendo difícil imaginar alguma política pública que não tangencie com algum direito fundamental ou princípio já estabelecido pela Lei Maior, que pode ser considerada uma matriz de políticas públicas.

$\mathrm{E}$ é uma matriz plenamente vinculante. $\mathrm{O} \S 1^{\circ}$ do art. $5^{\circ}$ da $\mathrm{CF}$, impõe que "as normas definidoras dos direitos e garantias fundamentais têm aplicação imediata". Desta forma, há um direcionamento a todas as instituições de quaisquer dos poderes para que efetivem de forma mais ampla possível os direitos assegurados pela Constituição. 
E a escolha desses mecanismos também serve para a despolitização do Poder Judiciário, que pode inclusive, na definição das políticas públicas, estando em coalização com determinado governante, agir no caminho majoritário ou contra-majoritário, ${ }^{44}$ a depender de seu alinhamento político, o que não se pode admitir de um poder que por natureza é imparcial.

Sobre a relação da aplicabilidade das normas constitucionais com as políticas públicas, necessário se faz o recurso à clássica divisão de José Afonso da Silva ${ }^{45}$ em relação as normas constitucionais em face de seu potencial de aplicabilidade.

Alguns dos direitos são de eficácia plena, ${ }^{46}$ são auto-aplicáveis, não exigindo atuação do legislador, produzindo efeitos desde a entrada em vigor da Constituição e sequer podem ser reduzidos pelo poder constituinte decorrente, sendo que tais direitos vinculam em alto grau a atuação dos poderes públicos e suas instituições, o que impõe a imediata adoção de ?? pública para implementar o direito, sendo também evidente a necessidade de fiscalização de um poder sobre o outro para a verificação da adoção da política púbica necessária e eficiência dessa para a consecução de aplicação do direito.

A Constituição traz direitos de eficácia contida ${ }^{47}$ (redutível, prospectiva ou plena restringível). Essas normas possuem aplicabilidade imediata e direta, não dependendo de leis posterior, mas podem ser restringidas a depender da discricionariedade do Poder Público. ${ }^{48}$

Também há direitos com eficácia limitada ${ }^{49}$ (mediata, reduzida, mínima diferida ou relativa complementável), consubstanciados naqueles que dependem de uma atuação posterior do poder público, sendo necessária uma regulação para que se permita a aplicação por completo do direito. Costuma-se dizer que, em relação a esses direitos, embora sejam relevantes, não há o mesmo nível de urgência em sua implementação, quando comparados com os direitos auto-aplicáveis, por dependerem de uma regulamentação infraconstitucional do direito. ${ }^{50}$

De qualquer forma, independente da classificação do grau de aplicabilidade da norma constitucional, não se afasta o dever de se implementar as políticas públicas para quaisquer deles, independentemente de qual Poder deva vir a atuação, Executivo ou Legislativo. E mesmo entre cada categoria de norma, é possível uma segmentação considerando níveis de exigência de cada uma. $E$ esses níveis de exigência é que devem nortear a intervenção judicial na fiscalização e imposição para que o poder público implemente esta ou aquela política com base em critérios exclusivamente jurídicos para a categorização das políticas. ${ }^{51}$

Diante do panorama constitucional, devem-se ter regras de categorização de aplicabilidade dos direitos para que se possa priorizar as políticas públicas. Deve haver uma identificação dos parâmetros de escolha da política pública e também de seu controle.52

Sob esse prisma Gilmar Mendes sugere a seguinte classificação sobre as fontes constitucionais de políticas públicas:

1) direitos sociais previstos em normas de aplicabilidade imediata (ou de aplicabilidade mediata já regulamentada), em que a exigibilidade é de grau alto e a intensidade do controle jurisdicional é forte; 2) direitos sociais previstos em normas constitucionais de aplicabilidade mediata (e ainda não regulamentada), caso em que o grau de exigibilidade é médio, assim como a possibilidade de 
intervenção e controle jurisdicional; e, finalmente; 3) objetivos que não atribuem direitos subjetivos, o que corresponde a políticas públicas de longo prazo, de modo que sua exigibilidade é mais baixa, além de estarem submetidas a um controle jurisdicional fraco. ${ }^{53}$

O Poder Judiciário (cujos integrantes, em tese impuros e separados dos comuns por sua toga, por sempre estar acima do embate e separado das partes já é visto como o possível guia no caminho para definir os caminhos de se chegar a algum lugar, ainda que não seja ao ponto final, mas sim à próxima esquina) é o ator que vai dar a palavra final em relação às políticas públicas, sendo necessário assim a demonstração de postulados que agreguem coerência, integridade, reflexão e isenção, na fundamentação nas análises de escolhas e até mesmo na forma de imposição das políticas públicas. ${ }^{54}$

\section{CONCLUSÕES A EVIDENCIAR A IMPORTÂNCIA DAS POLÍTICAS PÚBLICAS}

Temos que a política é um programa de ações. Há quem diga não serem nem normas nem atos, sendo essa constatação importante por ser o controle de constitucionalidade tradicionalmente exercido sobre normas e atos, mas é certo que a política os envolve e os tem como seu objeto, sendo assim possível o controle de constitucionalidade sobre elas. ${ }^{55}$ E este controle pode se dar tanto em relação às finalidades em si quanto aos meios usados para se atingir esse fim.

As ciências sociais, e, principalmente o direito, sempre exigido, não conseguem fornecer as explicações e fornecer a segurança tão almejadas. Ao contrário, muitas vezes, como já o foram, a psicologia, a antropologia, a sociologia e o direito podem servir ao propósito para justificar as diferenças existentes entre os indivíduos.

Mundialmente, percebe-se a falência ou insuficiência do Estado Providência. Mesmo em países desenvolvidos como os Estados Unidos, ${ }^{56}$ percebem-se as consequências de se estar no caminho de frente da linha do desenvolvimento. População obesa, socialmente dividida internamente, intentando se separar de nações consideradas impuras por meio de muros físicos, elevado número de pessoas vivendo na pobreza, dentro diversos outros problemas. Estar no primeiro lugar no que se refere ao percurso do trajeto retilíneo e uniforme do desenvolvimento não os torna muito diferentes de países que se encontram no final da fila da linha do progresso, onde os integrantes da fila contam com a submissão aos ditames do mercado globalizado, com a burocracia exacerbada que permite a corrupção em massa, com a concentração de rendas, com o desemprego e com a ineficiência. Tudo está a demonstrar que a linha do progresso pode ser outra que não a que todos almejam seguir.

E em todo esse turbilhão de vantagens e desvantagens trazidas pela própria vida social potencializada pela ciência, surge o direito. A constituição dos Estados Sociais e Democráticos de Direito tem o objetivo de resolver os problemas sociais. Com isso ganham força os fenômenos da panconstitucionalização a busca por novas formas de se traçar as diretrizes para a resolução dos problemas sociais

Já é percebida a ausência de confiança nos partidos políticos para a condução das políticas, eis que temos percebido que os interesses maiores dessas entidades muitas vezes nem é a consecução da melhor política pública, mas sim a melhor política própria. 
A democracia propiciada pelos legisladores também tem mostrado suas entranhas e os caminhos que expõem os reais interesses daqueles que, em tese, deveriam estar exercendo a representatividade.

Por outro lado, não há democracia sem conteúdo ${ }^{57}$ e verificação deste e sua afirmação por meio de processos argumentativos e não autoritários se mostra mais essencial do que nunca. Mas o intervencionismo não deve ser intransigente, devendo respeitar e fazer o contraponto entre a reserva do possível e o mínimo existencial exige. ${ }^{58}$

O Poder Executivo, seu aparelhamento e ineficiência para agir e para alocar os recursos, além da discricionariedade que muitas vezes é utilizada para cometer abusos, também mostra não saber muitas vezes o caminho a seguir, ou se o sabe, não tem a necessária eficiência para atingir os objetivos.

Nesse panorama, passou o Judiciário a ter importância no aspecto político, tendo que se imiscuir em questões polêmicas, seja em sede de controle difuso ou concentrado de constitucionalidade, sendo que nas Cortes Constitucionais, muitas vezes os que perderam no processo legislativo tentam melhor sorte no Poder Judiciário, ${ }^{59}$ mas esta já é questão a ser pensada em outro artigo, registre-se apenas, por oportuno, que a crítica a atuação do judiciário parte do ponto de que as decisões políticas deveriam ser tomadas por representantes do povo e não por técnicos, daí se falando em tecnocracia ou "judiciocracia", a ser considerada antidemocrática. ${ }^{60}$

E os desafios são grandes. Em sua gênese, o Direito foi concebido para resolver problemas passados, o caso concreto. Mas constantemente vem o julgador ser chamado para resolver problemas futuros, ${ }^{61}$ a exemplo de definir a melhor política pública a ser aplicada para resolver problemas futuros, que sempre se mostram novos até mesmo em face dos próprios avanços tecnológicos e sociais.

O Direito, entretanto, é um sistema apenas parcial da sociedade, mas é chamado sempre a resolver as expectativas sociais contraditórias. ${ }^{62} \mathrm{Na}$ sociedade complexa, o direito recebe a qualificação de ser restitutivo, em face da capacidade e liberdade de estabelecer relações contratuais. ${ }^{63}$ Embora por natureza devesse ser fechado, os aspectos cognitivos oriundos dos valores de uma sociedade complexa, devem ser mostrar presentes.

Assim, com o pensamento de Niklas Luhmann:

a partir da Teoria dos Sistemas, assume-se que o Direito é um sistema auto-
poiético-operacionalmente fechado, mas cognitivamente aberto -, o que torna
possível observar se a política influencia o discurso e a hermenêutica jurídicas
de forma "salutar" (como elemento cognitivo) ou de maneira indevida (substitu-
indo a argumentação jurídica pela política). ${ }^{64}$

E complexidade permite a existência de várias soluções para o mesmo problema, não se podendo falar em verdades absolutas.

Mas como vimos, não há tanta liberdade assim. As estruturas e possibilidades muitas vezes estão de tal forma amarradas que só há um caminho a seguir. $E$ nessa busca por segurança jurídica no meio da total insegurança surgem as súmulas vinculantes, decisões erga omnes, dentre diversos outros instrumentos que ostentam a missão de pacificação social 
e continuar a finalidade e necessidade de qualquer sociedade que é a existência de cooperação para que a própria sociedade continue a existir.

No constitucionalismo contemporâneo, a Constituição transformou-se na encarnação permanente de valores superiores da sociedade. O conteúdo material e de significados dela oriundos se irradia para todo o restante ordenamento jurídico, sendo que os valores, os comportamentos e os fins públicos traçados pela Carta Magna superam e condicionam a validade de todas as normas infraconstitucionais. Também afeta os demais poderes e até mesmo os indivíduos em sua esfera privada.

Isto porque os defensores de uma visão mais privatista do direito destacam e pregam por uma visão mais abstrata, centrada na autonomia do indivíduo, repugnando uma inflação dos direitos fundamentais. ${ }^{65}$ Há claro conflito ideológico, mas no caso da Constituição Federal de 1988, extremamente detalhista que incorporou uma infinidade de valores, a panconstitucionalização é uma realidade, inclusive legitimando o exercício do controle de constitucionalidade, ${ }^{66}$ a evidenciar a atuação do poder judiciário.

A Constituição encerraria uma proteção a determinados valores e direitos pelo interesse universal da própria sociedade na satisfação desses direitos. Mas é certo que o panorama vivido pelo Poder Constituinte pode tornar perene desejos que muitas vezes só seriam necessários no período em que atuou o Poder Constituinte, como regras paternalistas, protecionistas a determinados setores, corporativismos que, em outro momento da posterior história, podem se mostrar não tão necessários. A título de exemplos temos que a Constituição de 1988 para além de analítica é, em alguns aspectos prolixa e até corporativista, mas que, por estarem na Carta Maior, tornaram-se institucionalizados.

E os instrumentos para se levar ao Poder Judiciário a análise de políticas públicas são os mais variados, podendo-se citar: 1) ação civil pública com efeitos erga omnes (art. 129, III, da CF/88 e 16 da Lei 7.347/85); 2) ação direta de inconstitucionalidade de lei ou ato normativo federal ou estadual (art. 102, I, a, da CF/88); 3) ação declaratória de constitucionalidade de lei ou ato normativo federal (art. 102, I, a, da CF/88); 4) ação de inconstitucionalidade por omissão (art. 103, § $2^{\circ}$, da CF/88) 5) mandado de injunção (art. $5^{\circ}, \mathrm{XXI}$, e 102, I, q, e II, a, da $\mathrm{CF} / 88$ ); 6) arguição de descumprimento de preceito fundamental (art. 102, $\S 1^{\circ}$, da CF/88); 7) súmulas vinculantes (art. 102, $\S 2^{\circ}$, da CF/88); 8) ação popular (art. $5^{\circ}$, LXXIII, da CF/88) e 9) controle difuso de constitucionalidade a ser efetivado em quaisquer ações judiciais (art. $5^{\circ}, \mathrm{XXXV}$, da CF/88) . Como esse arcabouço de ações não se tem como deixar passar ao largo do Poder Judiciário as políticas públicas, sendo inevitável a judicialidade das políticas públicas, em se considerando os aspectos constitucionais. ${ }^{67}$

A constitucionalização do direito trouxe obrigações positivas e negativas para os membros do poder legislativo e executivo, a serem submetidos à jurisdição constitucional. E esta possui um papel importante perante a sociedade e o cidadão comum. Com certeza é mais fácil para qualquer integrante da sociedade buscar uma justiça a que entenda ter direito no capilarizado poder judiciário a percorrer todo o caminho democrático para o acesso ao legislador ou o caminho por demasiado discricionário de ser atendido pelo poder executivo. É certo que o Poder Judiciário tem um papel simbólico no imaginário social. ${ }^{68}$ 
No Brasil, no caminho trilhado pelo Supremo Tribunal Federal, diante das determinações detalhistas da nossa Constituição Federal, também se percebe uma inclinação política, na medida em que, seja pela via do controle concentrado ou do difuso, faz-se o cotejo entre as leis e atos dos demais poderes e a Carta Magna.

O STF, em temas de caráter político, não tem se omitido, o que se percebe em diversos julgados, como no que se deu o reconhecimento da inconstitucionalidade da vedação à progressão de regime aos autores de crimes hediondos. ${ }^{69}$ São várias as decisões em que o STF decidiu temas que contaram com o beneplácito da sociedade, temas que não tiveram o mesmo empenho por parte dos demais poderes.

É notória a influência de decisões da Suprema Corte norte-americana sobre o Supremo Tribunal Federal, pois em vários julgados o STF rememorou decisões da Corte Americana, seja sob a presidência de Warren ou dos Justices subsequentes. Ao tratar o STF do tema de perda de mandato parlamentar, do precedente Baker v. Carr de 1962, que discutira questões eleitorais (one man, one vote).$^{70}$ Analisando a questão da imunidade relativas dos Estados soberanos, citou a mudança de entendimento que se dera na Suprema Corte na década de 1950, quando a Corte modificou seu entendimento anterior que vigorava desde 1812, com o Schooner Exchange v. McFaddon. ${ }^{71}$ Ao se pronunciar sobre editais que impediam o acesso a cargo público de pessoas tatuadas, o STF citou o precedente da Corte norte-americana Miller vs. Califórnia de $1973 .^{72}$

A atuação de Corte Constitucional em questões que envolvam políticas públicas não é algo restrito ao direito pátrio, sendo verificada também em vários outros países. Na nossa é extremamente analítica, tratando de diversos pontos da vida social, podendo ser tida como substancialista, sendo certo, entretanto, serem necessários temperamentos. Seja para os procedimentalistas ou substancialistas, ambos compartilham a ideia de ser o Poder Judiciário uma instituição estratégica e essencial nas democracias contemporâneas, que potencializa e efetiva os mecanismos de checks and balances. ${ }^{73}$

Assim como está expressamente previsto na Constituição Federal a separação dos poderes, também estão os mecanismos de freios e contrapesos (modelo de balanceamento dos poderes) de uns com relação aos outros. Assim, sempre será possível o controle judicial das políticas públicas para decidir o grau de importância das políticas públicas escolhidas. ${ }^{74}$

E esse controle como vimos pode ser utilizado tanto para a defesa das minorias políticas quanto para justificar uma ação proveniente dos que ostentam maioria política, o que impera a definição de critérios claros de escolha e priorização de políticas públicas, quando o julgador apreciar os pedidos das ações judiciais e recursos lhe dirigidos.

Também não vislumbramos qualquer extrapolação de limites do referencial judicial, isto porque a função de controle de constitucionalidade vem bem delineada pela Constituição Federal. Os direitos fundamentais, inclusive os sociais são condições da democracia, e, em sendo o Poder Judiciário, o guardião desses direitos, tem o dever de fiscalizar e até mesmo impor a concreção desses direitos. Nesse sentido Souza Neto destaca que "a concretização judicial de direitos sociais fundamentais, independentemente de mediação legislativa, é um minus em relação ao controle de constitucionalidade". ${ }^{75}$ Assim, não há distanciamento 
e nem potencial de mitigação ${ }^{76}$ do modelo da democracia representativa nas decisões do STF sobre políticas públicas. Ao contrário, a democracia resta potencializada por permitir a dialética entre vários atores, entre eles, os que ostentam inclusive a legitimidade da representatividade do Executivo e Legislativo.

A efetivação das políticas públicas é imperiosa para manutenção do Estado Democrático Constitucional, cuja guarda foi originariamente atribuída ao Poder Judiciário, especificamente ao Supremo Tribunal Federal. Na medida em que o Supremo pronuncia-se em temas relacionados à concretização das políticas públicas, ou melhor, à efetivação dos direitos fundamentais, não se está dialogando entre a melhor ou pior estratégia, mas, sim, acerca do que a Constituição Federal traz como atribuição para o Supremo Tribunal Federal. Esses questionamentos superam os integrantes do Supremo e têm efeitos seculares. Trata-se da política judicial adotada pelo país. E, realmente, a atual sociedade não comporta um Tribunal silente. $^{77}$

\section{NOTAS}

1. Mestre em Direito e Doutora em Direito, com defesa em 22 de abril de 2020 e aprovação com louvor da tese intitulada "O Supremo Tribunal Federal e o tema do ativismo democrático-construtivo na implementação de políticas públicas: possibilidades, limites e casuística", sob orientação do Prof. Dr. Inocêncio Mártires Coelho, pelo Centro Universitário de Brasília- Uniceub.

2. BARROSO, Luís Roberto. Judicialização, ativismo judicial e legitimidade democrática. Anuário Iberoamericano de Justicia Constitucional, Madrid, n. 13, p. 17-32, 2009.

3. LEAL, Rogério Gesta. As responsabilidades políticas do ativismo judicial. In: LEAL, Mônia C. H.; LEAL, Rogério Gesta (org.). Ativismo judicial e déficits democráticos. Rio de Janeiro: Lumem Juris, 2011. p. 16.

4. BUCCI, Maria Paula Dallari; GASPARDO, Murilo (org.). Teoria do Estado. Sentidos contemporâneos. São Paulo: Saraiva, 2018, p. 15.

5. BUCCI, Maria Paula Dallari; GASPARDO, Murilo (org.). Teoria do Estado. Sentidos contemporâneos. São Paulo: Saraiva, 2018, p. 95.

6. BUCCI, Maria Paula Dallari; GASPARDO, Murilo (org.). Teoria do Estado. Sentidos contemporâneos. São Paulo: Saraiva, 2018, p. 17.

7. Duplo saco, fechado em ambas as extremidades e aberto no meio (por onde se dobra), formando duas bolsas iguais; us. ao ombro, para distribuir o peso dos dois lados.

8. CAMBI, Eduardo. Neoconstitucionalismo e neoprocessualismo. São Paulo: Editora Revista dos Tribunais, 2009, p. 266.

9. GRIMM, Dieter. Constituição e política. Belo Horizonte: Del Rey, 2006, p.11.

10. GRIMM, Dieter. Constituição e política. Belo Horizonte: Del Rey, 2006, p.13.

11. GRIMM, Dieter. Constituição e política. Belo Horizonte: Del Rey, 2006, p.10 e 14.

12. SIQUEIRA JR., Paulo Hamilton. Jurisdição constitucional política. São Paulo: Saraiva, 2017, p. $21 / 22$.

13. SIQUEIRA JR., Paulo Hamilton. Jurisdição constitucional política. São Paulo: Saraiva, 201, p. 22.

14. SIQUEIRA JR., Paulo Hamilton. Jurisdição constitucional política. São Paulo: Saraiva, 2017, p. 28. 
15. BECK, Ulrich; ZOLO, Danilo. A sociedade global do risco - uma discussão entre Ulrich Beck e

Danilo Zolo. Tradução de p Selvino J. Assmann. Disponível em: www.cfh.ufsc.br/ wfil/ulrich.htm.

16. CAVALCANTI, Eduardo Medeiros. Crime e sociedade complexa: uma abordagem interdisciplinar sobre o processo de criminalização. Campinas: LZN, 2005, p. 150.

17. KERCKHOVE, Derrick de. A pele da cultura - uma investigação sobre a nova realidade electrónica. Tradução de Luís Soares e Catarina Carvalho. Lisboa: Relógio d’Água, 1997, p. 126.

18. HARARI, Yuval Noah. Homo Deus: uma breve história do amanhã. Tradução Paulo Geiger. São Paulo: Companhia das Letras, 2016, p. 205.

19. HARARI, Yuval Noah. Homo Deus: uma breve história do amanhã; tradução Paulo Geiger. São Paulo: Companhia das Letras, 2016, p. 206.

20. COMTE-SPONVILLE, André. O ser-tempo: algumas reflexões sobre o tempo da consciência. Tradução de Eduardo Brandão. São Paulo: Martins Fontes, 2000, p. 53.

21. MAFFESOLI, Michel. A violência totalitária. Porto Alegre: Sulina, 2001, p. 25.

22. BECK. Ulrich. La sociedad del riesgo. Hacia una nueva modernidad. Tradução de Jorge Navarro, Daniel Jímenez e Maria Rosa Borrás. Barcelona: Paidós, 1998, p. 19.

23. BECK. Ulrich. La sociedad del riesgo. Hacia una nueva modernidad. Tradução de Jorge Navarro, Daniel Jímenez e Maria Rosa Borrás. Barcelona: Paidós, 1998, p. 28

24. BECK. Ulrich. La sociedad del riesgo. Hacia una nueva modernidad. Tradução de Jorge Navarro, Daniel Jímenez e Maria Rosa Borrás. Barcelona: Paidós, 1998, p. 43.

25. COMTE-SPONVILLE, André. O ser-tempo: algumas reflexões sobre o tempo da consciência. Tradução de Eduardo Brandão. São Paulo: Martins Fontes, 2000, p. 53.

26. VIRILIO, Paul. A inércia polar. Lisboa: Publicações Dom Quixote, 1993, p. 76.

27. GIDDENS, Anthony. As consequências da modernidade. 6. ed. Tradução de Raul Fiker. São Paulo: Editora UNESP, 1991, p. 69.

28. BAUMER, Franklin L. O pensamento europeu moderno. Tradução de Manuela Alberty e Artur Morão. Lisboa: Edições 70, v. II, 1990, p. 192.

29. ARENHART, Bianca Geórgia Cruz. O processo penal brasileiro à luz da filosofia da libertação de Enrique Dussel. In: COUTINHO, Jacinto Nelson de Miranda (coor.). Crítica à teoria geral do direito processual penal. Rio de Janeiro: Renovar, 2001, p. 208.

30. BARCELOS, Ana Paula de. Neoconstitucionalismo, Direitos fundamentais e controle das políticas públicas. Revista de Direito Administrativo, Rio de Janeiro, v. 240, p. 83-105, abr. 2005. p. 83-84.

31. SARMENTO, Daniel. Neoconstitucionalismo no Brasil: riscos e possibilidades. Revista brasileira de Estudos Constitucionais, Belo Horizonte: Fórum, ano 3, n.9, p.95-133, jan/mar. 2009. p. 98.

32. "Más bien, acogiendo una sugerencia de Louis Favoreu, por "constitucionalización del ordenamiento jurídico" propongo entender un proceso de transformación de un ordenamiento, al término del cual, el ordenamiento en cuestión resulta totalmente "impregnado" por las normas constitucionales. Un ordenamiento jurídico constitucionalizado se caracteriza por una Constitución extremadamente invasora, entrometida (pervasiva, invadente), capaz de condicionar tanto la legislación como la jurisprudencia y el estilo doctrinal, la acción de los actores políticos, así como las relaciones sociales." (GUASTINI, Ricardo. La 'Constitucionalización del ordenamiento jurídico: el caso italiano. In: CARBONELL, Miguel. Neoconstitucionalismo(s). Madrid: Editorial Trotta, 2003, p. 49).

33. BARROSO, Luís Roberto. Curso de direito constitucional contemporâneo: os conceitos funda- 
mentais e a construção do novo modelo. 7. ed. São Paulo: Saraiva, 2018, p. 283

34. BARROSO, Luís Roberto. Curso de direito constitucional contemporâneo: os conceitos fundamentais e a construção do novo modelo. 7. ed. São Paulo: Saraiva, 2018, p. 285.

35. BARROSO, Luís Roberto. Neoconstitucionalismo e constitucionalização do direito. Revista Nacional da Magistratura, Brasília: Escola Nacional da Magistratura, ano 1, n.2, p.26-73, out. 2006. p.28.

36. "En la primera acepción, como tipo de Estado de Derecho, cabe decir que el neoconstitucionalismo es el resultado de la convergencia de dos tradiciones constitucionales que con frecuencia han caminado separadas: una primera que concibe la Constitución como regla de juego de la competencia social y política, como pacto de mínimos que permite asegurar la autonomía de los individuos como sujetos privados y como agentes políticos a fin de que sean ellos, en un marco democrático y relativamente igualitario, quienes desarrollen libremente su plan de vida personal y adopten en lo fundamental las decisiones colectivas pertenecientes en cada momento histórico. En líneas generales, ésta es la tradición norteamericana originaria, cuya contribución básica se cifra en la idea de supremacía constitucional y en su consiguiente garantía jurisdiccional: dado su carácter de regla de juego y, por tanto de norma lógicamente superior a quienes participan en ese juego, la Constitución se postula como jurídicamente superior a las demás normas y su garantía se atribuye al más <neutro $>$ de los poderes, a aquel que debe y que mejor puede mantenerse al margen del debate político, es decir, al poder judicial." (SANCHÍS, Luis Prieto. Neoconstitucionalismo y ponderacion judicial. In: CARBONELL, Miguel. Neoconstitucionalismo(s). Madrid: Editorial Trotta, 2003, p. 124).

37. SARMENTO, Daniel. Neoconstitucionalismo no Brasil: riscos e possibilidades. Revista brasileira de Estudos Constitucionais, Belo Horizonte: Fórum, ano 3, n.9, p. 95-133, jan/mar. 2009. p.95

38. SARMENTO, Daniel. Neoconstitucionalismo no Brasil: riscos e possibilidades. Revista brasileira de Estudos Constitucionais, Belo Horizonte: Fórum, ano 3, n.9, p. 95-133, jan/mar. 2009. p.100.

39. GASCON ABELLÁN, Marina. Os limites da justiça constitucional: a invasão do âmbito político. Revista brasileira de Estudos Constitucionais, Belo Horizonte: Fórum, ano 3, n.9, p.71-92, jan/mar. 2009. p.76.

40. REISMAN, Leonardo; TONI, Jackson De. A formação do Estado Brasileiro e o impacto sobre as políticas públicas. In: MENDES, Gilmar Ferreira; PAIVA, Paulo. Políticas públicas no Brasil: uma abordagem institucional. São Paulo: Saraiva, 2017, p. 14.

41. REISMAN, Leonardo; TONI, Jackson De. A formação do Estado Brasileiro e o impacto sobre as políticas públicas. In: MENDES, Gilmar Ferreira; PAIVA, Paulo. Políticas públicas no Brasil: uma abordagem institucional. São Paulo: Saraiva, 2017, p.16.

42. REISMAN, Leonardo; TONI, Jackson De. A formação do Estado Brasileiro e o impacto sobre as políticas públicas. In: MENDES, Gilmar Ferreira; PAIVA, Paulo. Políticas públicas no Brasil: uma abordagem institucional. São Paulo: Saraiva, 2017, p.25 a 27.

43. REISMAN, Leonardo; TONI, Jackson De. A formação do Estado Brasileiro e o impacto sobre as políticas públicas. In: MENDES, Gilmar Ferreira; PAIVA, Paulo. Políticas públicas no Brasil: uma abordagem institucional. São Paulo: Saraiva, 2017, p.28.

44. RIBEIRO, Leandro Molhano; ARGUELHES, Diego Werneck; PEIXOTO, Vítor de Moraes. Processo Decisório, Judiciário e Políticas Públicas: Levando a decisão judicial a sério. Trabalho apresentado, $\mathrm{n}$. 33, p. 26-30, 2009. p. 3. Disponível em: direitorio.fgv.br/sites/direitorio.fgv.br.

45. SILVA, José Afonso da. Aplicabilidade das normas constitucionais. São Paulo: Malheiros. 1998, p. 89.

46. O autor indica como exemplos de normas de eficácia plena "as hipóteses contempladas nos arts. 21 (competência da União), 25 a 28 e 29 e 30 (competência dos Estados e Municípios), 145, 153, 155 e 156 (repartição de competências tributárias), e as normas que estatuem as atribuições dos órgãos dos Pode- 
res Legislativo, Executivo e Judiciário (arts. 48 e 49, 51 e 52, 70 e 71, 84 e 101-122)." (SILVA, José Afonso da. Aplicabilidade das normas constitucionais. São Paulo: Malheiros, 1998, p. 89).

47. "A peculiaridade das normas de eficácia contida configura-se nos seguintes pontos:

I - São normas que, em regra, solicitam a intervenção do legislador ordinário, fazendo expressa remissão a uma legislação futura; mas o apelo ao legislador ordinário visa a restringir-lhes a plenitude da eficácia, regulamentando os direitos subjetivos que delas decorrem para os cidadãos, indivíduos ou grupos. II Enquanto o legislador ordinário não expedir a normação restritiva, sua eficácia será plena; nisso também diferem das normas de eficácia limitada, de vez que a interferência do legislador ordinário, em relações a estas, tem o escopo de Ihes conferir plena eficácia e aplicabilidade concreta e positiva. III - São de aplicabilidade direta e imediata, visto que o legislador constituinte deu normatividade suficiente aos interesses vinculados à matéria de que cogitam. IV - Algumas dessas normas já contêm um conceito ético juridicizado (bons costumes, ordem pública etc.), como valor societário ou político a preservar, que implica a limitação de sua eficácia. $\vee$ - Sua eficácia pode ainda ser afastada pela incidência de outras normas constitucionais, se ocorrerem certos pressupostos de fato (estado de sítio, por exemplo)." (SILVA, José Afonso da. Aplicabilidade das normas constitucionais. São Paulo: Malheiros, 1998. p. 105).

48. O autor cita "alguns exemplos em que a própria Constituição de 1988 diminuiu o âmbito de incidência de uma norma constitucional de eficácia contida: a) direito de propriedade: da leitura dos incisos XXII e XXIV do art. 5o, percebe-se que o próprio legislador constituinte originário limitou o exercício do direito de propriedade; b) restrições a direitos fundamentais impostas pela decretação de estado de sítio: 0 art. 139 restringiu o âmbito de incidência de diversos direitos fundamentais, dentre os quais a liberdade de locomoção, a intimidade, a inviolabilidade domiciliar e a propriedade. Importante que se diga, ademais, que a restrição pode ser operada por conceitos ético-jurídicos, como no caso do art. 5o, XXV, em que o "iminente perigo público" autoriza à autoridade competente a imposição de restrições ao direito de propriedade, a partir do instituto da requisição administrativa." (DUTRA, Luciano. Direito Constitucional Essencial. 2. ed. Rio de Janeiro: Forense, 2016, p. 48).

49. "as normas constitucionais de eficácia limitada são de dois tipos: a) as definidoras de princípio institutivo ou organizativo, que, por brevidade, temos chamado de normas constitucionais de princípio institutivo; b) as definidoras de princípio programático, ou, simplesmente, normas constitucionais de princípio programático." (SILVA, José Afonso da. Aplicabilidade das normas constitucionais. São Paulo: Malheiros, 1998, p. 119).

50. CAVALCANTE FILHO, João Trindade. A constituição de 1988 como matriz de políticas públicas: direitos, deveres e objetivos no campo dos direitos sociais. In: MENDES, Gilmar Ferreira; PAIVA, Paulo. Políticas públicas no Brasil: uma abordagem institucional. São Paulo: Saraiva, 2017, p.41.

51. CAVALCANTE FILHO, João Trindade. A constituição de 1988 como matriz de políticas públicas: direitos, deveres e objetivos no campo dos direitos sociais. In: MENDES, Gilmar Ferreira; PAIVA, Paulo. Políticas públicas no Brasil: uma abordagem institucional. São Paulo: Saraiva, 2017, p.45.

52. BARCELOS, Ana Paula de. Neoconstitucionalismo, Direitos fundamentais e controle das políticas públicas. Revista de Direito Administrativo, Rio de Janeiro, v. 240, p. 83-105, abr. 2005. ISSN 2238-5177. P. 94. Disponível em: http://bibliotecadigital.fgv.br/ojs/index.php/rda/article/view/43620/44697. Acesso em: 09 mar. 2019. doi: http://dx.doi.org/10.12660/rda.v240.2005.43620.

53. CAVALCANTE FILHO, João Trindade. A constituição de 1988 como matriz de políticas públicas: direitos, deveres e objetivos no campo dos direitos sociais. In: MENDES, Gilmar Ferreira; PAIVA, Paulo. Políticas públicas no Brasil: uma abordagem institucional. São Paulo: Saraiva, 2017, p.46.

54. DE OLIVEIRA, Guilherme Fonseca; DE BRITO ALVES, Fernando. Democracia e ativismo judicial: atuação contramajoritária do judiciário na efetivação dos direitos fundamentais das minorias. Argumenta Journal Law, Jacarezinho, n. 20, p. 33-45, 2014. P. 41. Disponível em: http://seer.uenp.edu.br/index.php/ argumenta/article/view/432. Acesso em: 09 mar. 2019. 
55. COMPARATO, Fábio Konder. Ensaio sobre o juízo de constitucionalidade de políticas públicas. Revista de informação legislativa, Brasília, v. 35, n. 138, p. 39-48, 1998. P. 44-45. Disponível em: http:// www2. senado.leg.br/bdsf/bitstream/handle/id/496870/RIL138. pdf? sequence=1\#page=37. Acesso em: 09 mar. 2019.

56. Sobre o direito nos Estados Unidos ler Direito nos Estados Unidos de Arnaldo Sampaio de Moraes Godoy. GODOY, Arnaldo Sampaio de Moraes. Direito nos Estados Unidos. Barueri, SP: Manole, 2004.

57. LEAL, Mônia Clarissa Hening. Dworkin X Habermas, uma discussão acerca da legitimidade da jurisdição constitucional entre substancialismo e procedimentalismo: novas perspectivas. A\&C-Revista de Direito Administrativo \& Constitucional, Curitiba, v. 4, n. 17, p. 31-58, 2007. p. 55. Disponível em: http:// www.revistaaec.com/index.php/revistaaec/article/view/606. Acesso em: 16 mar. 2019.

58. HERRERA, Luiz Henrique Martim. Judicialização das políticas públicas de assistência à saúde: procedimentalismo versus substancialismo. Revista de Direito, [Valinhos], v. 12, n. 16, 2015. p. 87. Disponível em: http://revista.pgsskroton.com.br/index.php/rdire/article/view/1972/1874. Acesso em: 16 mar. 2019.

59. SARMENTO, Daniel. Neoconstitucionalismo no Brasil: riscos e possibilidades. Revista Brasileira de Estudos Constitucionais, Belo Horizonte: Fórum, ano 3, n.9, p. 95-133, jan/mar. 2009. p.101.

60. SARMENTO, Daniel. Neoconstitucionalismo no Brasil: riscos e possibilidades. Revista Brasileira de Estudos Constitucionais, Belo Horizonte: Fórum, ano 3, n.9, p. 95-133, jan/mar. 2009. p.118.

61. OLIBONI, Luiza Maria. O direito na sociedade complexa e as novas formas de imputação de responsabilidade civil por danos ambientais. Revista Ambiente e Educação, Rio Grande, v. 15, n. 1, p. 06, 2010. Disponível em: http://www.repositorio.furg.br/bitstream/handle/1/7260/882-4623-1-PB.pdf?sequence=1. Acesso em: 15 abr. 2019.

62. MARONA, Marjorie Corrêa. Pensando o direito em sociedades complexas - A teoria dos Sistemas Autopoiéticos como novo marco epistemológico. Revista Eletrônica DomTotal, Belo Horizonte, p. 08, 2019. Disponível em: http://domtotal.com/direito/uploads/1804.pdf. Acesso em: 15 abr. 2019.

63. ASSIS, Olney Queiroz. Manual de antropologia jurídica. São Paulo: Saraiva, 2011, p. 150.

64. CAVALCANTE FILHO, João Trindade. A constituição de 1988 como matriz de políticas públicas: direitos, deveres e objetivos no campo dos direitos sociais. In: MENDES, Gilmar Ferreira; PAIVA, Paulo. Políticas públicas no Brasil: uma abordagem institucional. São Paulo: Saraiva, 2017, p.34.

65. GUNTHER, Luiz Eduardo. A negociação coletiva do trabalho como direito fundamental: necessidade de afirmação da tutela dos direitos de personalidade na atividade empresarial mundializada. Revista Jurídica, Curitiba, v. 21, n. 5, p. 95-121, 2008. p. 103-104. Disponível em http://revista.unicuritiba.edu.br/ index.php/RevJur/article/download/118/92. Acesso em: 18 mar. 2019.

66. Pelo fato de em nossa Constituição estarem inseridas determinações sobre as atividades de programação e execução das finalidades do próprio Estado, legítimo se faz o exercício do controle de constitucionalidade, por todas as formas que este pode se materializar. No art. $3^{\circ}$, da CF/88, já se afirma que "constituem objetivos fundamentais da República Federativa do Brasil: I - construir uma sociedade livre, justa e solidária; II - garantir o desenvolvimento nacional; III - erradicar a pobreza e a marginalização e reduzir as desigualdades sociais e regionais e IV - promover o bem de todos, sem preconceitos de origem, raça, sexo, cor, idade e quaisquer outras formas de discriminação". Já com relação aos objetivos fundamentais é possível fazer ilações sobre os atos comissivos e omissivos aptos à implementação de tais objetivos (CANELA JUNIOR, Osvaldo. Controle Judicial de Políticas Públicas. São Paulo: Saraiva, 2011).

67. FIGUEIREDO, Marcelo. O controle das políticas públicas pelo Poder Judiciário no Brasil-uma visão geral. Revista Eletrônica da Faculdade de Direito, São Paulo, n. 1, p. 24, 2007. ISSN 1984-1094. Disponível em: https://revistas.pucsp.br/index.php/red/article/download/736/509. Acesso em: 09 mar. 2019.

68. BARROSO, Luís Roberto. Neoconstitucionalismo e constitucionalização do direito. Revista Nacional 
da Magistratura, Brasília: Escola Nacional da Magistratura, ano 1, n.2, p.26-73, out. 2006. p. 65.

69. STF, Habeas Corpus 82.959/SP (relator Ministro Marco Aurélio), julgado em 23/02/2006.

70. BRASIL. Supremo Tribunal Federal. MS 34064. Informativo STF. Brasília, 14 a 18 de março de 2016 - No 818. Disponível em: http://stf.jus.br/arquivo/informativo/documento/informativo818.htm. Acesso em: 22 de abr. de 2019.

71. BRASIL. Supremo Tribunal Federal. RHC 120598. Informativo STF. Brasília, 23 a 31 de março de 2015 - No 779. Disponível em: http://stf.jus.br/arquivo/informativo/documento/informativo779.htm. Acesso em: 22 abr. 2019

72. BRASIL. Supremo Tribunal Federal. RE 898450. Informativo STF. Brasília, 26 a 30 de setembro de 2016 - No 841. Disponível em: http://stf.jus.br/arquivo/informativo/documento/informativo841.htm. Acesso em: 22 abr. 2019.

73. HOMMERDING, Adalberto Narciso. Constituição, Poder Judiciário e Estado Democrático de Direito: a necessidade do debate "procedimentalismo versus substancialismo". Revista do Ministério Público do RS, Porto Alegre, n. 57, p. 23-44, 2006. p. 6-7. Disponível em: http://sisnet.aduaneiras.com.br/lex/ doutrinas/arquivos/310807.pdf.

74. ARENHART, Sérgio Cruz. As ações coletivas e o controle das políticas públicas pelo Poder Judiciário. Processo civil coletivo. São Paulo: Quartier Latin, 2005. Disponível em: http://repositorio.ufsc. br/xmlui/handle/123456789/87373.

75. SOUZA NETO, Cláudio Pereira et al. Teoria da Constituição: Estudos sobre o lugar da política no direito constitucional. Rio de Janeiro: Lumen Juris, 2003, p. 45.

76. LEAL, Rogério Gesta. O Estado-Juiz na Democracia Contemporânea: uma perspectiva procedimentalista. Porto Alegre: Livraria do Advogado, 2007, p. 31.

77. LEAL, Saul Tourinho. Ativismo ou altivez? O outro lado do Supremo Tribunal Federal. Belo Horizonte: Fórum, 2010, p. 195-196.

\section{REFERÊNCIAS}

ARENHART, Sérgio Cruz. As ações coletivas e o controle das políticas públicas pelo Poder Judiciário. Processo civil coletivo. São Paulo: Quartier Latin, 2005. Disponível em: http://repositorio. ufsc.br/xmlui/handle/123456789/87373.

ARENHART. Bianca Geórgia Cruz. O processo penal brasileiro à luz da filosofia da libertação de Enrique Dussel. In: COUTINHO, Jacinto Nelson de Miranda (coord.). Crítica à teoria geral do direito processual penal. Rio de Janeiro: Renovar, 2001.

ASSIS, Olney Queiroz. Manual de antropologia jurídica. São Paulo: Saraiva, 2011.

BARCELOS, Ana Paula de. Neoconstitucionalismo, Direitos fundamentais e controle das políticas públicas. Revista de Direito Administrativo, Rio de Janeiro: Renovar, v. 240, p. 83-105, abr. 2005.

BARROSO, Luís Roberto. Curso de direito constitucional contemporâneo: os conceitos fundamentais e a construção do novo modelo. 7. ed. São Paulo: Saraiva, 2018.

BARROSO, Luís Roberto. A dignidade da pessoa humana no direito constitucional contemporâneo: a construção de um conceito jurídico à luz da jurisprudência mundial. Belo Horizonte: Fórum, 2016. 
BARROSO, Luís Roberto. A judicialização da vida e o papel do Supremo Tribunal Federal. Belo Horizonte: Fórum, 2018.

BARROSO, Luís Roberto. Neoconstitucionalismo e constitucionalização do direito. Revista Nacional da Magistratura, Brasília, ano 1, n. 2, p.26-73, out. 2006.

BARROSO, Luís Roberto. Sem data venia: um olhar sobre o Brasil e o mundo. Rio de Janeiro: História Real, 2020.

BAUMER, Franklin L. O pensamento europeu moderno. Tradução de Manuela Alberty e Artur Morão. Lisboa: Edições 70, v. II, 1990.

BECK, Ulrich; ZOLO, Danilo. A sociedade global do risco - uma discussão entre Ulrich Beck e Danilo Zolo. Tradução de Selvino J. Assmann. Disponível em: www.cfh.ufsc.br/ wfil/ulrich.htm.

BECK. Ulrich. La sociedad del riesgo. Hacia una nueva modernidad. Tradução de Jorge Navarro, Daniel Jímenez e Maria Rosa Borrás. Barcelona: Paidós, 1998.

BRANDÃO, Pedro. O novo constitucionalismo pluralista latino-americano. Rio de Janeiro: Lumen Juris, 2015.

BUCCI, Maria Paula Dallari. Políticas públicas: reflexões sobre o conceito jurídico. São Paulo: Saraiva, 2006.

BUCCI, Maria Paula Dallari; GASPARDO, Murilo (org.). Teoria do Estado. Sentidos contemporâneos. São Paulo: Saraiva, 2018.

CAMBI, Eduardo. Neoconstitucionalismo e neoprocessualismo. São Paulo: Editora Revista dos Tribunais, 2009.

CANELA JUNIOR, Osvaldo. Controle Judicial de Políticas Públicas. São Paulo: Saraiva, 2011.

CAVALCANTI, Eduardo Medeiros. Crime e sociedade complexa: uma abordagem interdisciplinar sobre o processo de criminalização. Campinas: LZN, 2005.

COELHO, Inocêncio Mártires. Da hermenêutica filosofia a hermenêutica jurídica: fragmentos. São Paulo: Saraiva, 2015.

COELHO, Inocêncio Mártires. Interpretação constitucional. 4. ed. São Paulo: Saraiva, 2011.

COMPARATO, Fábio Konder. Ensaio sobre o juízo de constitucionalidade de políticas públicas. Revista de informação legislativa, Brasília, v. 35, n. 138, p. 39-48, 1998. Disponível em: http://www2.senado.leg. br/bdsf/bitstream/handle/id/496870/RIL138. pdf?sequence=1\#page=37. Acesso em: 09 mar. 2019.

COMTE-SPONVILLE, André. O ser-tempo: algumas reflexões sobre o tempo da consciência. Tradução de Eduardo Brandão. São Paulo: Martins Fontes, 2000.

DE OLIVEIRA, Guilherme Fonseca; DE BRITO ALVES, Fernando. Democracia e ativismo judicial: atuação contramajoritária do judiciário na efetivação dos direitos fundamentais das minorias. Argumenta Journal Law, Jacarezinho, n. 20, p. 33-45, 2014. Disponível em: http://seer.uenp.edu.br/index.php/argumenta/ 
article/view/432. Acesso em: 09 mar. 2019.

DUTRA, Luciano. Direito Constitucional Essencial. 2. ed. Rio de Janeiro: Forense, 2016.

FIGUEIREDO, Marcelo. O controle das políticas públicas pelo Poder Judiciário no Brasil - uma visão geral. Revista Eletrônica da Faculdade de Direito, São Paulo, n. 1, p. 24, 2007. ISSN 1984-1094. Disponível em: https://revistas.pucsp.br/index.php/red/article/download/736/509. Acesso em: 09 mar. 2019.

GASCON ABELLÁN, Marina. Os limites da justiça constitucional: a invasão do âmbito político. Revista brasileira de Estudos Constitucionais, Belo Horizonte: Fórum, ano 3, n.9, p.71-92, jan/mar. 2009.

GIDDENS, Anthony. As consequências da modernidade. 6. ed. tradução de Raul Fiker. São Paulo: Editora UNESP, 1991.

GODOY, Arnaldo Sampaio de Moraes. Direito nos Estados Unidos. Barueri, SP: Manole, 2004.

GRIMM, Dieter. Constituição e política. Belo Horizonte: Del Rey, 2006.

GUASTINI, Ricardo. La 'Constitucionalización del ordenamiento jurídico: el caso italiano. In: CARBONELL, Miguel. Neoconstitucionalismo(s). Madrid: Editorial Trotta, 2003.

GUNTHER, Luiz Eduardo. A negociação coletiva do trabalho como direito fundamental: necessidade de afirmação da tutela dos direitos de personalidade na atividade empresarial mundializada. Revista Jurídica, Curitiba, v. 21, n. 5, p. 95-121, 2008. p. 103-104. Disponível em http://revista.unicuritiba.edu.br/ index.php/RevJur/article/download/118/92. Acesso em: 18 mar. 2019.

HARARI, Yuval Noah. Homo Deus: uma breve história do amanhã. Tradução de Paulo Geiger. São Paulo: Companhia das Letras, 2016.

HARARI, Yuval Noah. Sapiens - Uma breve história da humanidade. Tradução de Janaína Marcoantonio. Porto Alegre: L\&PM, 2018.

HERRERA, Luiz Henrique Martim. Judicialização das políticas públicas de assistência à saúde: procedimentalismo versus substancialismo. Revista de Direito, [Valinhos], v. 12, n. 16, 2015. Disponível em: http://revista.pgsskroton.com.br/index.php/rdire/article/view/1972/1874. Acesso em: 16 mar. 2019.

HOCHHMAN, Gilberto; FARIA, Carlos Aurélio Pimenta de. Federalismo e políticas públicas. Rio de Janeiro: Editora Fiocruz, 2013.

HOMMERDING, Adalberto Narciso. Constituição, Poder Judiciário e Estado Democrático de Direito: a necessidade do debate "procedimentalismo versus substancialismo". Revista do Ministério Público do RS, Porto Alegre, n. 57, p. 23-44, 2006. Disponível em http://sisnet.aduaneiras.com.br/lex/doutrinas/ arquivos/310807.pdf. Acesso em: 16 mar. 2019.

KERCKHOVE, Derrick de. A pele da cultura - uma investigação sobre a nova realidade electrónica. Tradução de Luís Soares e Catarina Carvalho. Lisboa: Relógio d'Água, 1997.

LEAL, Rogério Gesta. O Estado-Juiz na Democracia Contemporânea: uma perspectiva procedimentalista. Porto Alegre: Livraria do Advogado, 2007. 
LEAL, Saul Tourinho. Ativismo ou altivez? O outro lado do Supremo Tribunal Federal. Belo Horizonte: Fórum, 2010.

LEAL, Mônia Clarissa Hening. Dworkin X Habermas, uma discussão acerca da legitimidade da jurisdição constitucional entre substancialismo e procedimentalismo: novas perspectivas. A\&C-Revista de Direito Administrativo \& Constitucional, Curitiba, v. 4, n. 17, p. 31-58, 2007. Disponível http://www.revistaaec. com/index.php/revistaaec/article/view/606. Acesso em: 16 mar. 2019.

LEFORT, Claude. A invenção democrática: os limites do totalitarismo. 2. ed. São Paulo: Editora Brasiliense, 1987.

LEITE, George Salomão; LEITE, Glauco Salomão; STRECK, Lênio Luiz. Neoconstitucionalismo: avanços e retrocessos. Belo Horizonte: Fórum, 2017.

MAFFESOLI, Michel. A violência totalitária. Porto Alegre: Sulina, 2001.

MARONA, Marjorie Corrêa. Pensando o direito em sociedades complexas - A teoria dos Sistemas Autopoiéticos como novo marco epistemológico. Revista Eletrônica DomTotal, Belo Horizonte, p. 08, 2019. Disponível em http://domtotal.com/direito/uploads/1804.pdf. Acesso em: 15 abr. 2019.

MENDES, Gilmar Ferreira; PAIVA, Paulo. Políticas públicas no Brasil: uma abordagem institucional. São Paulo: Saraiva, 2017.

OLIBONI, Luiza Maria. O direito na sociedade complexa e as novas formas de imputação de responsabilidade civil por danos ambientais. Revista Ambiente e Educação, Rio Grande, v. 15, n. 1, p. 06, 2010. Disponível em http://www.repositorio.furg.br/bitstream/handle/1/7260/882-4623-1-PB. pdf?sequence=1. Acesso em: 15 abr. 2019.

RIBEIRO, Leandro Molhano; ARGUELHES, Diego Werneck; PEIXOTO, Vitor de Moraes. Processo Decisório, Judiciário e Políticas Públicas: Levando a decisão judicial a sério. Trabalho apresentado, n. 33, p. 26-30, 2009. Disponível em: direitorio.fgv.br/sites/direitorio.fgv.br.

SANCHÍS, Luis Prieto. Neoconstitucionalismo y ponderacion judicial. In: CARBONELL, Miguel. Neoconstitucionalismo(s). Madrid: Editorial Trotta, 2003.

SARMENTO, Daniel. Neoconstitucionalismo no Brasil: riscos e possibilidades. Revista brasileira de Estudos Constitucionais, Belo Horizonte, ano 3, n.9, p.95-133, jan/mar. 2009.

SILVA, José Afonso da. Aplicabilidade das normas constitucionais. São Paulo. Malheiros. 1998.

SIQUEIRA JR., Paulo Hamilton. Jurisdição constitucional política. São Paulo: Saraiva, 2017.

VIRILIO, Paul. A inércia polar. Lisboa: Publicações Dom Quixote, 1993.

Recebido em: 22/09/2020

Aceito em: 30/12/2020 